Disponível em

http://www.anpad.org.br/rac

RAC, Curitiba, v. 14, n. 4, art. 7,

pp. 684-702, Jul./Ago. 2010

\title{
Relações de Poder e Mudanças Pós-aquisição Internacional na Rede de Relacionamentos da Adquirida
}

\author{
Power Relations and International Post-acquisition Changes in the Relationship Network \\ of the Acquired Firm
}

\author{
Luciedi Temporal Gomes Esper * \\ Mestre em Administração pela PUC/MG. \\ Professora da PUC/Minas, Belo Horizonte/MG, Brasil. \\ Sérgio Fernando Loureiro Rezende \\ Doutor em Marketing pela Lancaster University, Reino Unido. \\ Professor da PUC/Minas, Belo Horizonte/MG, Brasil. \\ Ângela França Versiani \\ Doutora em Administração pela USP. \\ Professora da PUC/Minas, Belo Horizonte/MG, Brasil. \\ Humberto Elias Garcia Lopes \\ Doutor em Administração pela UFMG. \\ Professor da PUC/Minas, Belo Horizonte/MG, Brasil. \\ Liliane de Oliveira Guimarães \\ Doutora em Administração pela EAESP/FGV. \\ Professora da PUC/Minas, Belo Horizonte/MG, Brasil. \\ Roberto Gonzalez Duarte \\ Doutor em Administração pela Cambridge University, Reino Unido. \\ Professor da UFMG, Belo Horizonte/MG, Brasil.
}

* Endereço: Luciedi Temporal Gomes Esper

Pontifícia Universidade Católia de Minas Gerais (PUC/Minas), Programa de Pós-Graduação em Administração, Av. Itaú, 525, bairro Dom Bosco, Belo Horizonte/MG, 30730-280. E-mail: luciedi@terra.com.br

Copyright (C) 2010 RAC. Todos os direitos, inclusive de tradução, são reservados. É permitido citar parte de artigos sem autorização prévia desde que seja identificada a fonte. 


\title{
RESUMO
}

Embasados na perspectiva de redes industriais e na literatura de canais de distribuição, neste artigo analisamos poder e mudanças pós-aquisição internacional, ocorridas nos relacionamentos da adquirida com fornecedores e compradores. Especificamente, investigamos se e como a variável poder influencia mudanças pós-aquisição internacional na rede de relacionamentos da adquirida. Para tanto, desenvolvemos um estudo de caso, com base em entrevistas semiestruturadas com representantes da adquirente, adquirida, fornecedores e compradores. Os principais resultados apontam que a aquisição ocasionou mudanças em práticas organizacionais de caráter econômico e não econômico, nos relacionamentos da adquirida com fornecedores e compradores. Além disso, revelam que a adquirente utilizou fontes de poder coercitivas e/ou não coercitivas para introduzir tais mudanças. A utilização dessas fontes, por sua vez, esteve atrelada ao grau de dependência dos fornecedores e compradores em relação à adquirente. Baeados nesses resultados, desenvolvemos novo modelo de pesquisa, com cinco novas hipóteses de pesquisa para testes empíricos futuros.

Palavras-chave: mudanças pós-aquisição; poder; rede de relacionamentos; relacionamento comprador-vendedor.

\begin{abstract}
Based on the industrial network perspective and the distribution channel literature, this article deals with power and international post-acquisition changes that occurred in the relationships of the acquired firm with suppliers and buyers. Specifically, we investigate if and how the power variable affects international post-acquisition changes at the network level of the acquired firm. To do so, we developed a case study based on semi-structured interviews with a number of individuals from the acquirer, the acquired firm, suppliers and buyers. The main results point out that the acquisition triggered economic and non economic organizational practice changes at the supplier and buyer levels. Furthermore, they indicate that the acquirer used coercive and non coercive sources of power in order to introduce these changes. The use of these sources of power, in turn, was associated with the degree of dependence of suppliers and buyers in relation to the acquirer. Based on these results, we have developed a model with five new hypotheses that can be tested in future empirical studies.
\end{abstract}

Key words: post-acquisition changes; power; relationship networks and buyer-supplier relationships. 


\section{INTRODUÇÃO}

A partir da década de 90, a grande movimentação de recursos financeiros, originados de fusões e aquisições, tem evidenciado a crescente importância dessas operações como forma de expansão internacional (Child, Faulkner, \& Pitkethly, 2001). Por exemplo, dados mostram que, em 2005, o montante global de capital referente à entrada em mercados estrangeiros por meio de aquisições superou seis vezes a média de US\$ 117 milhões, registrada entre 1990 e 2000 (United Nations Conference on Trade and Development [UNCTAD], 2006). Em que pese tal crescimento, inúmeros estudos têm revelado elevados índices de fracasso, decorrentes dessas operações (Barros, 2003). H. Anderson, Havila e Salmi (2001), por exemplo, assinalam que as expectativas de congruência entre a adquirente e a adquirida e, consequentemente, de retornos econômico-financeiros satisfatórios têm sido substituídos por processos de integração malsucedidos e resultados financeiros pífios.

Em busca da identificação de fatores que determinam operações exitosas de fusões e aquisições e as alternativas para minimizar as dificuldades de integração pós-aquisição, vários pesquisadores estrangeiros (Child et al., 2001; Jemison \& Sitkin, 1986) e brasileiros (Cançado \& Tanure, 2005; Duarte, 2001, 2003) têm-se dedicado à análise de aquisições internacionais. Na literatura resultante desse esforço de pesquisa, observa-se que, tradicionalmente, a ênfase tem sido dada aos atores diádicos - adquirente e adquirida (Graebner \& Eisenhardt, 2004), o que significa que outros atores envolvidos, tais como fornecedores e compradores, têm sido, em maior ou menor grau, desconsiderados. Dito de outra maneira, esses estudos têm assumido, mesmo que implicitamente, que a aquisição afeta apenas a adquirente e a adquirida (H. Anderson, et al., 2001; Rezende \& Duarte, 2004).

Contudo, mais recentemente, pesquisadores nórdicos (J. Anderson, Häkansson, \& Johanson, 1994; H. Anderson et al., 2001; Halinen, Salmi, \& Havila, 1999; Havila \& Salmi, 2000; Öberg \& Holstrom, 2006) têm argumentado que a análise de processos de aquisição deva incluir não somente os atores diretamente envolvidos na transação, mas também a rede de relacionamentos da adquirida, normalmente composta por seus principais fornecedores e compradores (Halinen et al., 1999). Para tanto, propõem a utilização da perspectiva de redes industriais (Häkansson \& Snehota, 1995), para investigar mudanças ocasionadas por processos de aquisição internacional nos relacionamentos da adquirida. De maneira geral, nessa perspectiva, tem-se como pressuposto que um relacionamento entre atores está conectado, diretamente ou indiretamente, a outros relacionamentos (J. Anderson et al., 1994). Em nível agregado, essa conectividade revela interdependência estrutural de atividades, recursos e atores, denominada redes de relacionamentos ou redes de negócios (Häkansson, 1982; Hakansson \& Snehota, 1995; Hilal \& Hemais, 2001) $)^{(1)}$.

Alicerçado nessa perspectiva e a partir da sugestão de Hertz (1998), considera-se, neste trabalho, que uma aquisição possa desencadear mudanças nos relacionamentos da adquirida, em especial com os fornecedores e compradores (Bocconcelli, Snehota, \& Tunisini, 2006; Halinen et al., 1999), uma vez que, em função da interdependência dos atores em redes, o que acontece em termos de mudanças pósaquisição em um relacionamento diádico afeta, em maior ou menor grau, outros relacionamentos (Halinen et al., 1999). Em casos mais extremos, mudanças em um relacionamento propagam-se para toda a rede de negócios (Hertz, 1998), gerando, como resultado, uma nova configuração de atores, atividades e recursos (Easton \& Lundgren, 1992; Häkansson \& Snehota, 1995).

Um ponto que se destaca nessa discussão é introduzido por Forsgren e Olsson (1992). Os autores suecos sugerem que a seleção das mudanças pós-aquisição seja dependente das pressões, influências e poder de barganha dos diversos atores envolvidos, ou seja, as mudanças que são efetivamente implementadas nos relacionamentos da adquirida, no período pós-aquisição, parecem estar sujeitas ao poder interorganizacional da adquirente-adquirida em relação aos fornecedores e compradores da adquirida (Häkansson \& Ford, 2002; Wilkinson \& Young, 2002). É interessante assinalar que as sugestões de pesquisas futuras, propostas por Öberg e Holstrom (2006), se coadunam com essa proposta na medida em que esses autores argumentam que uma análise mais refinada de mudanças 
pós-aquisição, em redes de relacionamento, envolve considerar as relações de poder dos atores envolvidos.

Tomando-se como referência essa linha de raciocínio, surgiu-nos a indagação de se e como a variável poder influenciaria mudanças pós-aquisição internacional na rede de relacionamentos da adquirida. Com base nessa pergunta de pesquisa, formula-se o objetivo deste artigo como sendo o de analisar o papel da variável poder em processos de aquisição internacional, os quais, neste trabalho, são entendidos como eventos que potencialmente deflagram mudanças nos relacionamentos da adquirida com fornecedores e compradores (Hertz, 1998).

A fim de atingir esse objetivo, realizou-se um estudo de caso de natureza qualitativa que envolve um processo de aquisição internacional ocorrido no mercado brasileiro ${ }^{(2)}$. Os principais resultados apontam que a aquisição ocasionou mudanças em práticas organizacionais de caráter econômico e não econômico, nos relacionamentos da adquirida com fornecedores e compradores. Além disso, revelam que a adquirente utilizou fontes de poder coercitivas e/ou não coercitivas para introduzir tais mudanças. A utilização dessas fontes, por sua vez, esteve atrelada ao grau de dependência dos fornecedores e compradores em relação à adquirente. Tais resultados forneceram subsídios para a formulação de cinco novas hipóteses de pesquisa para testes empíricos futuros.

Visando apresentar tal discussão, organizou-se este artigo em quatro seções. Na primeira, procede-se à revisão da literatura que aborda inicialmente os estudos sobre mudanças pós-aquisição em redes de relacionamento para, posteriormente, vinculá-los à literatura de poder interorganizacional, em especial àquela derivada dos estudos em canais de distribuição. Na segunda seção, detalha-se a construção metodológica para, na terceira seção, apresentar e analisar os dados. Finalmente, as duas seções do artigo contêm, respectivamente, o modelo de pesquisa e as hipóteses dali decorrentes, as quais, eventualmente, poderão servir como ponto de partida para futuros estudos empíricos.

\section{MUdANÇAS PÓS-AQUISIÇÃo EM REDES DE RELACIONAMENTOS}

Os estudos sobre processos de aquisição têm-se concentrado no processo de integração entre adquirente e adquirida e no desempenho da aquisição (Child et al., 2001; Duarte, 2003), abordando, por exemplo, transferência e integração de práticas organizacionais, choques culturais e aspectos estratégicos, tais como a criação de valor pós-aquisição (Barros, 2003; Datta, 1991; Duarte, 2001; Haspeslagh \& Jemison, 1991; Shrivastava, 1986). Ao proceder a uma ampla revisão dessa literatura, H. Anderson et al. (2001) e, mais recentemente, Graebner e Eisenhardt (2004) chamaram atenção para o fato de que tais estudos assumem, mesmo que implicitamente, que os efeitos de processos de aquisição internacional se restringem unicamente aos dois atores diretamente envolvidos, aqui denominados díade: adquirente e adquirida. Essa tendência em focar nos atores diádicos é também ressaltada por H. Anderson, Holtström e Öberg (2003), em estudo que pesquisou as decisões tomadas por órgãos governamentais que analisam e/ou aprovam processos de aquisição. Os autores concluíram que, tanto as empresas adquirentes como as autoridades governamentais, raramente levam em conta, em suas decisões, os relacionamentos da adquirida.

Diante dessas constatações e inspirados pela perspectiva de redes industriais (Häkansson, 1982; Häkansson \& Snehota, 1995), diversos trabalhos tais como o de Halinen et al. (1999), Havila e Salmi (2000; 2002) e H. Anderson et al. (2001) têm insistido na ideia de que a análise de processos de aquisição devam considerar não somente os atores envolvidos diretamente na transação - adquirente e adquirida - mas também o ambiente em que esses atores estão inseridos, ou seja, a rede de relacionamentos da adquirida com fornecedores e compradores. Para tanto, esses autores avançam a proposta de que processos de aquisição ocorram em contextos relacionais (Havila \& Salmi, 2000), em que atores são vinculados por meio de atividades e recursos (J. Anderson et aL., 1994; Hilal \& Hemais, 2001). 
Um aspecto ressaltado por esses estudos, particularmente crítico para este trabalho, diz respeito ao poder interorganizacional dos atores envolvidos (Forsgren \& Olsson, 1992). De acordo com Häkansson e Ford (2002), mudanças em contextos relacionais normalmente envolvem alterações nos atores diretamente envolvidos e nos seus respectivos relacionamentos. Isso porque um ator que introduz determinadas mudanças é sempre dependente da reação dos atores a ele conectados para efetivamente implementá-las (Faria, 2007; Forsgren \& Olsson, 1992;). Nesse caso, mudanças têm de ser aprovadas e, em algumas situações, absorvidas por outros atores, visto que, caso contrário, existe a possibilidade de serem recusadas (Easton \& Lundgren, 1992). Por essas razões, atores frequentemente se deparam com a necessidade de coagir outros para realização de seus objetivos e/ou fazer concessões aos objetivos e às iniciativas de outros (Faria \& Wensley, 2002; Ritter \& Ford, 2004).

Seguindo essa linha de raciocínio, Forsgren e Olsson (1992), Rezende e Duarte (2004) e Öberg e Holstrom (2006) buscaram relacionar mudanças pós-aquisição e poder interorganizacional. Forsgren e Olsson (1992), por exemplo, sugere que mudanças pós-aquisição nos relacionamentos da adquirida com fornecedores e compradores são suscetíveis de equilíbrio de poder dos atores envolvidos. Tal conclusão, de maneira similar, é revelada na pesquisa de Rezende e Duarte (2004), os quais sugerem que poder potencial e/ou exercido pode ser tratado como variável mediadora entre processos de aquisição e tipos de mudanças pós-aquisição. A natureza independente da variável poder também é destacada no trabalho de Öberg e Holstrom (2006), que a consideram um dos principais elementos determinantes das mudanças pós-aquisição nos relacionamentos da adquirida.

Como a dimensão política é considerada apenas perifericamente pela perspectiva de redes industriais (Faria, 2007; Faria \& Wensley, 2002), buscou-se aprofundar a discussão da variável poder no contexto de mudanças pós-aquisição internacional nos relacionamentos da adquirida com fornecedores e compradores, a partir da discussão de poder interorganizacional, proposta pela literatura de canais de distribuição (El-Ansary \& Stern, 1972; Frazier, 1983; Gaski, 1984). A utilização dessa literatura como aporte teórico auxiliar à perspectiva de redes industriais justifica-se por duas razões: (a) historicamente, existe interface entre essas literaturas, uma vez que, por exemplo, consideram como objeto de análise relacionamentos diádicos inseridos em mercados organizacionais (Eiriz \& Wilson, 2006). Nesse sentido, pode-se afirmar que tal sobreposição minimiza incongruências, quando essas literaturas são consideradas em um mesmo quadro de análise; (b) a literatura de canais de distribuição oferece sólido arcabouço teórico acerca de poder interorganizacional que, de alguma forma, tem sido respaldado por inúmeros testes empíricos nos últimos 40 anos; para ampla revisão dessa literatura, ver Gaski, (1984).

Para essa literatura, o poder interorganizacional pode ser entendido como "a habilidade de um ator em provocar mudanças no comportamento de outrem” (Gaski, 1984, p. 10). Também pode ser caracterizado a partir de dois elementos principais: fontes de poder (El-Ansary \& Stern, 1972; Hunt \& Nevin, 1974; Johnson, Sakano, Cote, \& Onzo, 1993; Kutschker, 1982; Wilkinson \& Kipnis, 1978) e grau de dependência (Berthon, Pitt, Ewing, \& Bakkeland, 2003; Brown, Lusch, \& Nicholson, 1995; Cook, 1977; Emerson, 1962; Lusch, 1976).

O primeiro elemento, fontes de poder, diz respeito aos recursos de um ator que, eventualmente, podem ser utilizados para influenciar o comportamento de outro ator (Kutschker, 1982). Cabe destacar que, para que esses recursos sejam traduzidos em fontes de poder, eles devem ser escassos e valorizados por uma das partes (Cook, 1977). Para El-Ansary e Stern (1972), as fontes de poder podem ser categorizadas em coercitivas e não coercitivas. Enquanto as primeiras significam que um dos atores tem habilidade de mediar punição, envolvendo ameaças ou sanções negativas, as segundas implicam consentimento do ator influenciado, sem envolver relutância.

O segundo elemento sugerido pela literatura de canais de distribuição é o grau de dependência entre os atores. Embasados na teoria de dependência, originalmente proposta por Emerson (1962), ElAnsary e Stern (1972) e Hunt e Nevin (1974), sugerem que a extensão da dependência de um ator em canais de distribuição seja diretamente relacionada ao comprometimento desse ator em termos de política de marketing desenvolvida por outros atores do canal e ao volume de vendas realizado com 
outro ator, e inversamente relacionada ao número de fornecedores disponíveis para determinado recurso.

Em suma, a partir da perspectiva de redes industriais, assume-se que os efeitos de aquisições internacionais extrapolam as fronteiras da díade, deflagrando mudanças nos relacionamentos da adquirida com fornecedores e compradores (Faria, 2007). Esse processo pode, por sua vez, ser afetado pela variável poder na medida em que os atores que introduzem determinadas mudanças estão sujeitos à reação dos atores a eles conectados. Os elementos de poder interorganizacional, aqui destacados, são as fontes de poder, categorizadas em coercitivas e não coercitivas, e o grau de dependência dos atores envolvidos no processo de aquisição.

\section{METODOLOGIA}

Para a condução da pesquisa que originou este trabalho, utilizou-se o método de caso de natureza qualitativa (George \& Bennett, 2005; Miles \& Huberman, 1994). Para Halinen e Törnroos (2005), esse método é o mais adequado para se entender redes de relacionamentos, que constituem formas organizacionais de elevada complexidade (Poldony \& Page, 1998). Ao concordar com tal posição, Öberg, Henneberg e Mouzas (2007) ressaltam a importância do estudo de caso de natureza qualitativa, em investigações que objetivam entender influências de processos de aquisição em redes de relacionamentos.

Com relação à coleta de dados, o primeiro passo adotado neste estudo foi a seleção do processo de aquisição, cuja escolha foi balizada pelos seguintes critérios. Inicialmente, de acordo com os parâmetros estabelecidos pelo UNCTAD (2000), foi estabelecido que a aquisição internacional deveria envolver, pelo menos, a compra de $10 \%$ das ações ou cotas da adquirida. O segundo critério referia-se ao ano de aquisição, sendo consideradas somente empresas adquiridas entre 1997 e 2000. Como a coleta de dados ocorreu nos anos de 2003-2004, tal critério justifica-se pela intenção de minimização de problemas relacionados à lembrança de eventos passados (Golden, 1992), sem deixar de considerar a temporalidade do impacto da aquisição (Araújo, 2003), o que significa que os efeitos disparados pelo processo de aquisição podem não ser imediatos (Öberg \& Holstrom, 2006). O terceiro e último critério de seleção estabelecia que as empresas adquiridas deveriam ser manufaturas, já que o presente trabalho está teoricamente alicerçado na perspectiva de redes industriais (Häkansson \& Snehota, 1989, 1995) e na literatura de canais de distribuição (Gaski, 1984).

Tendo esses critérios como parâmetros, selecionou-se um processo de aquisição ocorrido em 1999 no setor de alimentos. Inicialmente foram investigados a adquirente e adquirida. Com base na indicação desses atores (Brito, 1999), incluiu-se na presente investigação mais dois fornecedores e dois compradores. Apesar de a determinação desse número de atores ser, em maior ou menor grau, arbitrária, tem-se observado que pesquisas em redes industriais, tais como o estudo de U. Anderson, Forsgren e Holm (2002), têm optado por selecionar até três fornecedores e/ou até três compradores para ilustrar a rede de relacionamentos de um determinado ator.

Paralelamente à seleção do processo de aquisição, foram construídos três roteiros de entrevistas: um para a díade (adquirente-adquirida), um para os fornecedores e um para os compradores. Nesses roteiros buscava-se basicamente identificar os atores envolvidos na aquisição, o processo de aquisição, as principais mudanças nas práticas organizacionais dos fornecedores e compradores e as possíveis alterações nas relações de poder entre os atores envolvidos.

Apoiados nesses roteiros de entrevistas, foram realizadas sete entrevistas com representantes da adquirente, adquirida, fornecedores e compradores, entre maio de 2003 e março de 2004. Somados a esses dados, procedeu-se a um levantamento de dados secundários, por meio da utilização de documentos internos das empresas pesquisas, press releases, relatórios anuais e notícias de jornais, tais como Gazeta Mercantil, Folha de São de Paulo e Valor. Esse levantamento permitiu não somente 
aumentar a validade interna de pesquisa (Miles \& Huberman, 1994), como possibilitou efetuar a triangulação dos dados (Jick, 1979).

Para a análise dos dados, adotou-se o processo de "combinação sistemática”, sugerido por Dubois e Gaade (2002), o qual envolve o uso simultâneo de indução e dedução (Goldstone, 1997). Por um lado, tem-se como ponto de partida teorias e/ou hipóteses já estabelecidas na literatura (Eisenhardt, 1989). Por outro lado, utilizam-se dados empíricos para refinar e/ou repensar as teorias que, inicialmente, nortearam a análise de dados (Araújo, 2003).

Essa análise iniciou-se com o mapeamento dos tipos de mudanças pós-aquisição (Rezende \& Duarte, 2004). Esse mapeamento se deu indutivamente, observando-se que tais mudanças se referiam às práticas de contratação, de produção, de qualidade, de auditoria, de custeio, de precificação, de monitoramento de vendas, de novos produtos e de marketing e merchandising. Posteriormente, tais mudanças foram categorizadas em econômicas e não econômicas. As mudanças econômicas se referem àquelas que tiveram impacto imediato e direto no faturamento da adquirida, enquanto as não econômicas não possuíam, necessariamente, uma relação imediata e direta com tal faturamento. No primeiro grupo (mudanças econômicas) foram enquadradas as mudanças nas práticas de custeio e de precificação, enquanto no segundo grupo (mudanças não econômicas) foram classificadas as mudanças nas práticas de contratação, de qualidade, de auditoria, de monitoramento, de vendas, de novos produtos e de marketing e de merchandising.

Prosseguindo a análise de dados, agora sob prisma dedutivo, o foco foi verificar se essas mudanças estavam relacionadas à variável poder. Nesse ponto, a nossa atenção voltou-se para aquilo que foi efetivamente mudado, a pedido ou por imposição da díade, indicando, portanto, manifestação real de poder (Provan, Beyer, \& Kruytbosch, 1980). Além disso, partindo da sugestão de Hunt e Nevin (1974), Lusch (1976) e Gaski (1984), associamos a manifestação real de poder às fontes de poder do influenciador que, no caso do presente estudo, é representado pela adquirente. Para tanto, utilizamos a dicotomia coercitiva - não coercitiva (El-Ansary \& Stern, 1972; Gaski, 1984; Hunt \& Nevin, 1974; Johnson et al., 1993; Lusch, 1976; Wilkinson, 1979). Conforme discutido anteriormente, as fontes coercitivas envolvem potencial de punição e ameaça, não havendo consentimento do influenciado. Por sua vez, as fontes consideradas não coercitivas não envolvem relutância, pois a permissão e a aceitação do influenciado conferem naturalmente poder ao influenciador.

Por meio desse procedimento, foi possível identificar e categorizar as mudanças pós-aquisição no relacionamento da díade com cada fornecedor e com cada comprador investigado e associá-las às fontes de poder coercitivas e não coercitivas. A partir desse momento, avançou-se na análise, procedendo a uma análise comparativa de dados, conforme recomendações de Ragin (1987) e Miles e Huberman (1994). No nosso caso, essa análise foi realizada em nível intragrupo, em que se buscou verificar o grau de semelhança e/ou diferença, entre fornecedores e compradores, das mudanças pósaquisição encontradas e respectivas fontes de poder. Com isso, encerrou-se a análise de dados, acreditando ter atingindo nível satisfatório de saturação de dados.

\section{RESULTADOS}

\section{Conhecendo os Atores do Processo de Aquisição}

Conforme se menciona na seção anterior, o processo de aquisição aqui analisado ocorreu no setor de alimentos e envolveu os seguintes atores. A adquirente é representada por duas multinacionais norteamericanas: Pillsbury e General Mills. Na época da aquisição, a primeira estava presente no Brasil por meio dos sorvetes Haagen-Dazs e das Massas Frescarini, enquanto a segunda comercializava os produtos da marca Yoplait no país. A adquirida denomina-se Forno de Minas, empresa familiar fundada em 1990, cujo principal produto era o pão de queijo congelado. Em 1999, período da 
aquisição, a empresa produzia aproximadamente 15 mil toneladas/ano de pão de queijo, empregava cerca de 500 pessoas e tinha faturamento de $\mathrm{R} \$ 50$ milhões anuais.

Os dois fornecedores escolhidos foram a Leiteria de Minas e o Laticínios Ita. A Leiteria de Minas foi fundada em 1995 pela mesma família proprietária da Forno de Minas e fornecia o queijo-de-minasmeia-cura, principal insumo na fabricação de pão de queijo. Como a Leiteria não tinha produção suficiente para atender à necessidade de queijo da Forno de Minas, na época da aquisição, a empresa comprava esse mesmo insumo do Laticínios Ita. Esse fornecedor foi fundado em 1991, com a finalidade de produzir produtos derivados do leite que servissem de matéria-prima no processo produtivo de outras empresas. Cabe destacar que no período de implementação das mudanças pósaquisição nesses fornecedores, a adquirida absorvia, praticamente, $100 \%$ da produção da Leiteria de Minas e 85\% do Laticínios Ita, denotando, portanto, maior grau de dependência da primeira empresa em relação à multinacional.

Quanto aos compradores, o Carrefour foi escolhido como principal representante do segmento de varejo e a Rei do Mate como exemplo do segmento de food service, o qual é composto por empresas que fornecem alimento pronto para consumo fora do lar, tais como lanchonetes, cafeterias e padarias. O Carrefour é uma rede francesa de hipermercados que atua no Brasil desde 1975. No país envolveuse em uma grande aquisição em 1999 com a compra de 23 unidades das Lojas Americanas. Por meio dessa aquisição, criou-se a bandeira Champion de supermercados, a qual foi extinta seis anos depois. Na época da aquisição, o Carrefour comprava a linha de produtos congelados fornecida pela Forno de Minas (pão de queijo tradicional, pão de queijo coquetel e sabores, folheados e a linha de pão de batata recheado), tanto para a venda ao consumidor como para a comercialização do produto pronto para consumo nas padarias internas dos supermercados. É interessante notar que a primeira encomenda de pão de queijo pelo Carrefour ocorreu em 1990 e foi de 720 unidades. Nove anos mais tarde, o pedido de compras anual totalizou 480 milhões de unidades. Já a Rei do Mate é uma rede de casas de chá, fundada na década de 50 em São Paulo. Somente em 1992, com a opção pelo sistema de franquia, é que a empresa efetivamente iniciou o processo de expansão que, aliás, foi vertiginoso. Por exemplo, em 2003, a rede contava com seis lojas próprias e 142 franqueadas, presentes em 14 Estados brasileiros, atendendo a um milhão de clientes/mês. De acordo com as entrevistas realizadas, observou-se que o grau de dependência do Carrefour e da Rei do Mate em relação à adquirida era "relativamente baixo", já que o pão de queijo não era considerado o principal produto vendido por essas empresas. Tendo esse parâmetro em vista, cabe salientar que esse grau de dependência possuía uma variação entre esses compradores, sendo mais baixo para o Carrefour do que para a Rei do Mate.

\section{Mudanças Pós-aquisição em Fornecedores}

Ao se identificar e, posteriormente, analisar as mudanças pós-aquisição ocorridas no relacionamento da adquirida com a Leiteria de Minas e com o Laticínios Ita, chegou-se à conclusão de que 17 mudanças foram deflagradas nesses relacionamentos, em decorrência da aquisição da Forno de Minas pela Pillsbury/General Mills. Dessas, 10 foram relacionadas à variável poder. Isso significa que essas mudanças pós-aquisição no relacionamento com os fornecedores foram a pedido ou por imposição da adquirente, o que caracteriza manifestação real do poder desse ator (ver Tabela 1). 
Tabela 1

\section{Mudanças Pós-aquisição no Relacionamento com os Fornecedores. Número Total de Mudanças x Número de Mudanças Relacionadas a Poder}

\begin{tabular}{lccc}
\hline \multicolumn{1}{c}{ Mudanças Pós-aquisição } & Leiteria de Minas & Laticínios Ita & Total de Mudanças \\
\hline $\begin{array}{l}\text { Número total de mudanças } \\
\begin{array}{l}\text { Número e percentual de mudanças } \\
\text { relacionadas a poder }\end{array}\end{array}$ & 8 & 9 & 17 \\
\hline
\end{tabular}

Nota. Fonte: Elaborada pelos autores

De maneira mais detalhada, inicialmente, nota-se que dois tipos de mudanças não econômicas são peculiares ao relacionamento com a Leiteria de Minas: mudanças nas práticas de contratação e nas de produção. A mudança nas práticas de contratação diz respeito às relações contratuais entre adquirenteadquirida e fornecedor, as quais garantiram uma preferência de compra do queijo-de-minas-meia-cura fornecido pela Leiteria de Minas. Já a mudança nas práticas de produção indicou a modernização e ampliação da capacidade de produção do fornecedor. É importante salientar que as mudanças nas práticas de contratação foram vistas como forma de recompensa por parte do proprietário do laticínio, o que significa que tal mudança foi relacionada à fonte de poder não coercitiva. Já a mudança nas práticas de produção foi, de certa maneira, imposta pela adquirente, na medida em que houve ameaça de não credenciamento desse fornecedor; portanto trata-se de fonte de poder coercitiva.

As demais mudanças observadas ocorreram tanto no relacionamento com a Leiteria de Minas como nos Laticínios Ita. Por exemplo, as mudanças nas práticas de qualidade e de auditoria se referem, respectivamente, às exigências de qualidade de produtos e processos, e de controle adotadas pela multinacional. Para a Leiteria de Minas, antes da aquisição, os níveis e padrões de qualidade, tanto para os produtos como para os processos, baseavam-se essencialmente nas medidas estipuladas pela legislação em vigor e eram aceitos pelos órgãos de vigilância sanitária. Porém não atendiam aos padrões mínimos estabelecidos pela multinacional. Assim, as mudanças nos níveis de qualidade e de controle em tal fornecedor foi intensa, o que não impossibilitou problemas constantes de não conformidade de seus produtos e inúmeras devoluções por parte da adquirente. Na adoção de tais práticas, observa-se uma imposição e exigência da multinacional por meio de intenso controle e exaustivas solicitações de melhoramento de processos e produtos na Leiteria de Minas, o que caracteriza fonte de poder coercitiva. Já no relacionamento com o Laticínios Ita, essas mudanças foram descritas e percebidas de forma mais amena, já que havia não somente menor dependência do fornecedor em relação à multinacional, bem como as práticas de qualidade e de auditoria dessa empresa enquadravam-se razoavelmente dentro dos padrões estabelecidos pela adquirente. Em relação a esse último ponto, os depoimentos sinalizam que esse fornecedor era extremamente preocupado com as questões de qualidade, muito antes do processo de aquisição, tendo, nesse período, adotado espontaneamente as normas de qualidade sugeridas pela futura adquirente. Assim, os padrões de qualidade superaram os estabelecidos e exigidos pelos órgãos de fiscalização. Além disso, os procedimentos adotados pela empresa já levavam em conta boas práticas produtivas e de baixos níveis de contaminação. Em função desse quadro, a aquisição não mudou a relação do laticínio com as práticas de qualidade, tampouco com as de auditoria, mas as aprimorou.

Finalmente, as mudanças nas práticas de custeio e de precificação, aqui classificadas como econômicas, estão fundamentadas nas fontes de poder coercitivas, independendo, portanto, do fornecedor. A mudança nas práticas de custeio para a Leiteria de Minas foi drástica, porque, antes da aquisição, tanto a forma de negociação como os controles de custos eram feitos de forma totalmente informal e integrada com a Forno de Minas. Como essas empresas eram gerenciadas em conjunto, os custos do leite e, por consequência, do queijo eram imediatamente absorvidos pela adquirida. Após a aquisição, essa flexibilização e repasse dos custos do leite foram imediatamente abolidos com a desvinculação das empresas. A forma de operar da multinacional, muito mais complexa, formal e impositiva foi imediatamente sentida pelo fornecedor. Nesse mesmo sentido, foi analisada a mudança 
nas práticas de precificação. Logo após a aquisição, houve pressão por parte da adquirente sobre o preço do leite e os atritos se iniciaram. Conforme relatado por um dos entrevistados, a adquirente sempre exigia menores preços, mesmo conhecendo os custos da Leiteria de Minas, já que tinha em mãos uma tabela de custos fornecida pela empresa em cada negociação. No relacionamento com o Laticínios Ita, a mudança nas práticas de custeio e de precificação também foram identificadas e associadas às fontes de poder coercitivas, já que, após a aquisição, a empresa foi ainda mais pressionada quanto à redução de preços e diminuição de repasse de custos. Esses resultados estão sintetizados na Tabela 2 seguinte, a qual aponta as mudanças pós-aquisição na Leiteria de Minas e no Laticínios Ita e as relaciona com o tipo de mudança e as fontes de poder.

Tabela 2

Tipos de Mudanças Pós-aquisição e Fontes de Poder no Relacionamento com os Fornecedores.

\begin{tabular}{lcccc}
\hline \multirow{2}{*}{ Mudanças Pós-aquisição } & \multicolumn{2}{c}{ Tipo da Mudança } & \multicolumn{2}{c}{ Fontes de Poder } \\
\cline { 2 - 5 } & $\begin{array}{c}\text { Leiteria de } \\
\text { Minas }\end{array}$ & Laticínios Ita & $\begin{array}{c}\text { Leiteria de } \\
\text { Minas }\end{array}$ & Laticínios Ita \\
\hline Práticas de contratação & Não econômica & - & Não coercitiva & - \\
Práticas de produção & Não econômica & - & Coercitiva & - \\
Práticas de qualidade & Não econômica & Não econômica & Coercitiva & Não coercitiva \\
Práticas de auditoria & Não econômica & Não econômica & Coercitiva & Não coercitiva \\
Práticas de custeio & Econômica & Econômica & Coercitiva & Coercitiva \\
Práticas de precificação & Econômica & Econômica & Coercitiva & Coercitiva \\
\hline
\end{tabular}

Nota. Fonte: Elaborada pelos autores

\section{Mudanças Pós-aquisição em Compradores}

Seguindo a mesma lógica adotada para relatar as mudanças pós-aquisição em fornecedores, buscouse inicialmente identificar e analisar as mudanças pós-aquisição ocorridas nos relacionamentos da adquirida com os compradores, aqui representados pelo Carrefour e pela Rei do Mate. Os dados revelam que tais mudanças foram observadas somente no relacionamento com a rede de casas de chá. Das sete mudanças, quatro podem ser associadas à variável poder. Quanto ao comprador Carrefour, as mudanças verificadas no relacionamento com a adquirente não puderam ser associadas ao processo de aquisição ora estudado. Isso porque a aquisição da Forno de Minas pela Pillsbury/General Mills não alterou a maneira como os dois atores se relacionavam, tampouco implicou mudanças nas práticas organizacionais vigentes entre eles. Ademais, não se identificou nenhuma alteração nas relações de poder, sendo que as regras formais e informais do relacionamento continuaram sofrendo enorme influência do Carrefour após a aquisição. Por conseguinte, os dados referentes aos compradores dizem respeito somente a Rei do Mate (ver Tabela 3). 
Tabela 3

Mudanças Pós-aquisição no Relacionamento com os Compradores: Número Total De Mudanças x Número de Mudanças Relacionadas a Poder.

\begin{tabular}{lccc}
\hline \multicolumn{1}{c}{ Mudanças Pós-aquisição } & Rei do Mate & Carrefour & Total de Mudanças \\
\hline Número total de mudanças & 7 & 0 & 7 \\
$\begin{array}{l}\text { Número e percentual de mudanças } \\
\text { relacionadas a poder }\end{array}$ & 4 & 0 & 4 \\
\hline
\end{tabular}

Nota. Fonte: Elaborada pelos autores

De maneira mais detalhada, os dados apontam somente mudanças não econômicas, as quais se referem às práticas de contratação, de monitoramento de vendas, de novos produtos e de marketing/merchandising. A mudança nas práticas de contratação introduzida pela adquirente foi, de acordo com um dos entrevistados, "muito bem" recebida e estabelecia que a multinacional, a partir daquele momento, seria o único fornecedor de pão de queijo para toda a rede de casas de chá por meio da assinatura de um contrato formal. Para o entrevistado, tal formalização ratificou o compromisso entre as empresas, tornando o relacionamento "uma parceria”. Por sua vez, a mudança nas práticas de monitoramento de vendas, introduzida pela multinacional e realizada em conjunto com a Rei do Mate, foi considerada "positiva” pelo comprador, uma vez que possibilitou o aumento de vendas de ambas as empresas. Tal mudança consistia na verificação e acompanhamento do volume de vendas de pão de queijo em cada loja da franquia.

As práticas de novos produtos foram outra mudança não econômica observada no relacionamento com a Rei do Mate após a aquisição e estão relacionadas ao desenvolvimento de receitas e de embalagens exclusivas de pão de queijo para a Rei do Mate. Finalmente, as práticas de marketing e merchandising foram a última mudança identificada no relacionamento da adquirida com a Rei do Mate e significaram que, após a aquisição, a multinacional passou a ter papel ativo na concepção de marketing do comprador, apresentando sugestões quanto à disposição do produto no ponto de venda até o desenvolvimento conjunto de campanhas de venda, as quais envolviam até mesmo esforços de venda do próprio mate, principal produto da rede. Em síntese, todas as mudanças ocorridas no relacionamento com a Rei do Mate são de caráter não econômico e, de acordo com os entrevistados, foram percebidas de forma amena, estando, portanto, fundamentadas em fontes de poder não coercitivas (ver Tabela 4).

Tabela 4

Tipos de Mudanças Pós-aquisição e Fontes de Poder no relacionamento com os compradores

\begin{tabular}{lll}
\hline \multicolumn{1}{c}{ Mudanças Pós-aquisição } & $\begin{array}{c}\text { Tipo da Mudança } \\
\text { Rei do Mate }\end{array}$ & $\begin{array}{c}\text { Fontes de Poder } \\
\text { Rei do Mate }\end{array}$ \\
\hline $\begin{array}{l}\text { Práticas de contratação } \\
\begin{array}{l}\text { Práticas de monitoramento de } \\
\text { vendas }\end{array}\end{array}$ & Não econômica & Não coercitiva \\
$\begin{array}{l}\text { Práticas de novos produtos } \\
\begin{array}{l}\text { Práticas de marketing e } \\
\text { merchandising }\end{array}\end{array}$ & Não econômica & Não coercitiva \\
\hline
\end{tabular}

Nota. Fonte: Elaborada pelos autores 


\section{PODER E MUDANÇAS PÓS-AQUISIÇÃo INTERNACIONAL}

A análise do processo de aquisição retratado neste trabalho, aqui representado pelas adquirentes Pillsbury e General Mills, a adquirida Forno de Minas e sua rede de fornecedores e compradores, indica que as mudanças pós-aquisição podem ser mais bem compreendidas, a partir das relações de poder dos atores envolvidos (Forsgren \& Olsson, 1992; Öberg \& Holstrom, 2006), as quais são manifestadas pelas fontes de poder (Gaski, 1984) coercitivas e não coercitivas (El-Ansary \& Stern, 1972). Os dados sugerem que tais fontes de poder assumem o papel de moderadora entre processos de aquisição e mudanças pós-aquisição.

Mais especificamente, os resultados apontam que o processo de aquisição ocasionou mudanças econômicas e não econômicas nos relacionamentos da adquirida. Para as mudanças econômicas foram utilizadas somente fontes de poder coercitivas por parte da adquirente. Por exemplo, as mudanças nas práticas de custeio e de precificação ocorridas nos relacionamentos da adquirida com a Leiteria de Minas e com o Laticínios Ita foram, em maior ou menor grau, impostas pela multinacional, à medida que a empresa norte-americana sinalizou com a possibilidade de descredenciamento dessas empresas. No caso de mudanças não econômicas ocorridas nos relacionamentos da adquirida com fornecedores e com compradores, a adquirente fez uso tanto de fontes de poder coercitivas quanto de não coercitivas. Nesse caso, observou-se que a utilização de tais fontes estavam vinculadas ao grau de dependência do fornecedor e/ou comprador em relação à adquirente. Por exemplo, as mudanças nas práticas de qualidade e de auditoria na Leiteria de Minas, fornecedor mais dependente da multinacional, esteve sujeita à coerção por parte da multinacional, enquanto essas mesmas mudanças no Laticínios Ita foram objeto de negociação entre o fornecedor e a empresa norte-americana. Esses resultados foram utilizados como ponto de partida para a formulação do modelo de pesquisa (ver Figura 1) e serão discutidos detidamente a seguir.

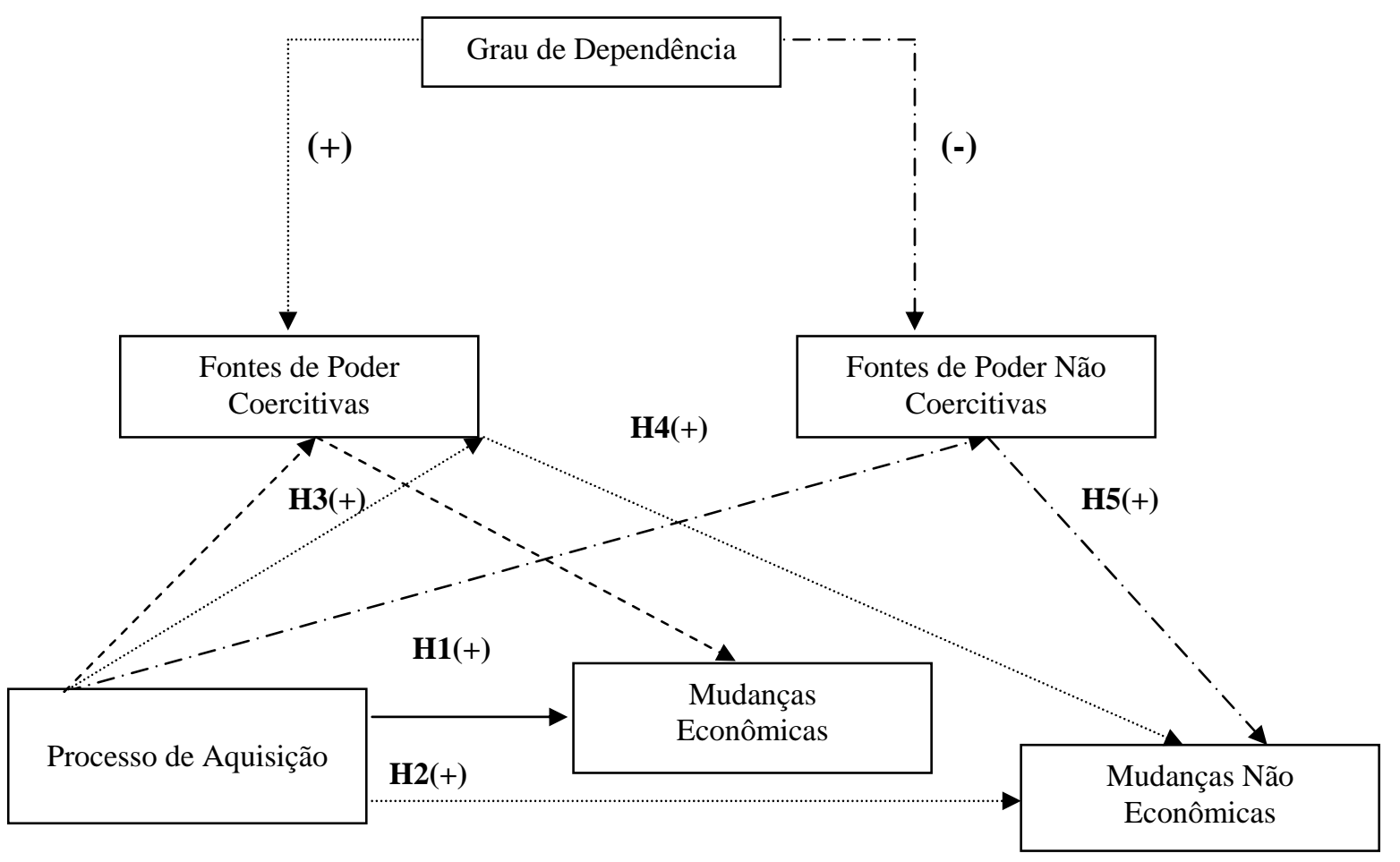

Figura 1: Modelo de Pesquisa: Mudanças Pós-aquisição Internacional e Fontes de Poder Fonte: Elaborado pelos autores Legenda: H1: $\mathrm{H} 2$ : H3: -...-H4: . . ..........H5: 
Conforme visto na descrição e análise de dados, o processo de aquisição da Forno de Minas pela Pillsbury/General Mills deflagrou uma série de mudanças nos relacionamentos da adquirida com fornecedores e com compradores. De certa maneira, tal resultado vai ao encontro da abordagem advogada por J. Anderson et al. (1994), H. Anderson et al. (2001), Halinen et al. (1999), Havila e Salmi, (2000), e Öberg e Holstrom, (2006) de que mudanças pós-aquisição extrapolam a díade, alcançando os relacionamentos diretos e indiretos da adquirida. Ao refinar esse resultado, os dados contidos neste trabalho permitem propor a existência de uma relação direta e positiva entre processos de aquisição internacional e mudanças econômicas e não econômicas nos relacionamentos com os fornecedores e compradores da adquirida (H. Anderson et al., 2001). Isso significa que aquisições internacionais podem ser concebidas como eventos catalisadores (Hertz, 1998) de mudanças conectadas (Halinen et al., 1999), econômicas e não econômicas (Rezende \& Duarte, 2004), que se estendem aos outros relacionamentos além da díade. Esses resultados são formulados nas duas primeiras hipóteses deste trabalho.

H1- Ceteris paribus, existe uma relação positiva entre processos de aquisição internacionais e mudanças econômicas nos relacionamentos da adquirida com fornecedores e compradores.

H2 - Ceteris paribus, existe uma relação positiva entre processos de aquisição internacionais e mudanças não econômicas nos relacionamentos da adquirida com fornecedores e compradores.

Se a relação entre processos de aquisição internacional e mudanças nos relacionamentos dos fornecedores e compradores, mais recentemente, tem merecido maior atenção por parte de inúmeros pesquisadores internacionais (Havila \& Salmi, 2000) e nacionais (Rezende \& Duarte, 2004), pode-se observar que as hipóteses um e dois avançam tal entendimento, ao sugerir que tais mudanças possam ser categorizadas em econômicas e não econômicas. Interessa observar que tal resultado encontra, de alguma maneira, ressonância no estudo recente de Freitas, Rezende e Castro (2008); eles mostram que o processo de aquisição internacional ocasionou ambos os tipos de mudança na rede de fornecedores da adquirida.

O resultado seguinte sinaliza que as mudanças econômicas e não econômicas disparadas por processos de aquisição podem ser mais bem compreendidas, se levarmos em consideração as relações de poder existentes entre adquirente, adquirida, fornecedores e compradores (Öberg \& Holstrom, 2006). Mais especificamente, os resultados apontam que a variável fontes de poder atua como moderadora entre processos de aquisição e mudanças econômicas e não econômicas. Dito de outra maneira, o poder manifesto da adquirente em relação aos relacionamentos da adquirida é variável causal de mudanças pós-aquisição internacional. Porém tal poder atua em nível secundário em relação à principal variável independente do presente estudo, que é o próprio processo de aquisição. Esse raciocínio pode ser ilustrado pelo caso apresentado neste trabalho, à medida que o processo de aquisição da Forno de Minas pela Pillsbury/General Mills não alterou o equilíbrio de poder dos atores envolvidos: adquirente, adquirida, fornecedores e compradores, ou seja, os atores que detinham maior poder antes da aquisição foram, de acordo com os dados analisados, considerados os atores mais poderosos no período pós-aquisição. Se não houve nenhuma alteração nesse equilíbrio de poder, os dados indicam que o poder da adquirente, por meio da utilização de fontes coercitivas e não coercitivas de poder, foi exercido com o intuito de tornar a implementação de mudanças pós-aquisição mais efetiva. Isso caracteriza o papel moderador do variável poder, à medida que tal elemento é utilizado como mecanismo para introduzir as mudanças requeridas pelo ator mais poderoso. Esses resultados são formulados em mais três hipóteses (hipóteses três, quatro e cinco), as quais relacionam processos de aquisição, fontes de poder, mudanças pós-aquisição e grau de dependência entre adquirente e fornecedor e/ou comprador.

A terceira hipótese postula que fontes de poder coercitivas moderam a relação entre processos de aquisição internacional e mudanças econômicas. Isso significa que mudanças ocorridas nos relacionamentos da adquirida com fornecedores e compradores de caráter econômico, mais notadamente práticas de custeio e de precificação, estão sujeitas à imposição da adquirente. É interessante observar que o grau de dependência entre adquirente e fornecedor e/ou comprador não interfere nessa relação. 
H3 - Em condição ceteris paribus e sob influência do exercício de fontes de poder coercitivas da adquirente, processos de aquisição tendem a ocasionar mudanças econômicas nos relacionamentos da adquirida com fornecedores e compradores.

Para as mudanças não econômicas, os resultados do presente estudo sinalizam que há diferença importante no que tange à utilização de fontes de poder coercitivas, e não coercitivas. Isso pode ser visto nas hipóteses quatro e cinco. A hipótese quatro sugere que a adquirente tende a utilizar fontes de poder coercitivas, para introduzir mudanças não econômicas nos relacionamentos em que os fornecedores e compradores são mais dependentes da adquirente. Ou seja, pelo fato de esses atores possuírem maior grau dependência em relação à adquirente e, portanto, apresentarem menor capacidade de resistência à implementação de mudanças pós-aquisição, a adquirente tende a utilizar seu poder de maneira coercitiva por meio da imposição de suas diretrizes. Tais relações podem ser vistas na hipótese quatro.

H4 - Em condição ceteris paribus e sob influência de fontes de poder coercitivas da adquirente, processos de aquisição tendem a ocasionar mudanças não econômicas nos fornecedores e/ou compradores de maior dependência da adquirente.

Raciocínio semelhante é utilizado para formular a próxima hipótese. De acordo com a hipótese cinco, existe a tendência de a adquirente fazer uso de fontes de poder não coercitivas para introduzir mudanças não econômicas em fornecedores e/ou compradores de menor dependência. Nesse caso, a menor relação de dependência entre os atores faz com que a implementação de mudanças pósaquisição esteja sujeita a um processo de barganha entre as partes (Öberg \& Holstrom, 2006): mecanismos diversos, tais com premiação e legimitação (El-Ansary \& Stern, 1972; Emerson, 1962), são utilizados pela adquirente.

H5 - Em condição ceteris paribus e sob influência de fontes de poder não coercitivas da adquirente, processos de aquisição tendem a ocasionar mudanças não econômicas nos fornecedores e/ou compradores de menor dependência da adquirente.

Em nível teórico, esses três últimos resultados reforçam a ideia de Forsgren e Olsson (1992) e de Rezende e Duarte (2004) de que o poder é variável crítica para o estudo de mudanças pós-aquisição internacional nos relacionamentos da adquirida com fornecedores e compradores. Entretanto há uma diferença importante no que se refere ao papel assumido por essa variável. Para esses autores, o poder atua como variável mediadora, o que significa que processos de aquisição internacional tendem a alterar as relações de poder entre os atores envolvidos. Entretanto este estudo aponta uma situação em que, conforme discutido anteriormente, não houve nenhum desequilíbrio de poder entre os atores envolvidos. Houve, outrossim, a utilização do poder por parte da adquirente, ator mais poderoso antes e após a aquisição, como mecanismo para facilitar a implementação das mudanças pós-aquisição. Isso caracteriza o papel de moderadora da variável poder, em processos de aquisição internacional.

\section{CONSIDERAÇÕES FINAIS}

A partir da constatação de que mudanças pós-aquisição não são confinadas às fronteiras da díade (H. Anderson et al., 2001; Havila \& Salmi, 2002), desenvolveu-se um estudo de caso, de natureza qualitativa, com o objetivo de analisar o papel da variável poder em processos de aquisição internacional, tendo em vista os relacionamentos da adquirida com fornecedores e compradores. Os resultados aqui discutidos apontam que o poder manifesto da adquirente, via fontes de poder, atua como moderador de mudanças nos relacionamentos da adquirida, ocasionadas por processos de aquisição. Esses resultados serviram de base para a formulação de um modelo de pesquisa por meio do qual cinco novas hipóteses de pesquisa são sugeridas. Enquanto as duas primeiras estabelecem a relação entre processos de aquisição e mudanças pós-aquisição, econômicas e não econômicas, nos 
relacionamentos da adquirida com fornecedores e compradores, as demais propõem relações entre processos de aquisição, tipos de mudanças pós-aquisição e fontes de poder.

Tendo tais resultado em consideração, acredita-se que o presente trabalho propõe um entendimento mais refinado de processos de aquisição, já que articula as variáveis fontes de poder (El-Ansary \& Stern, 1972), tipos de mudanças pós-aquisição (Rezende \& Duarte, 2004) e grau de dependência (Cook, 1977; Emerson, 1962). Como tais variáveis são representativas de literaturas distintas - canais de distribuição e redes industriais - pode-se avançar a idéia de que o nosso trabalho tem o mérito de conectar literaturas (in)dependentes para explicar um fenômeno que só mais recentemente tem merecido maior atenção por parte dos pesquisadores, qual seja, as mudanças pós-aquisição internacional atingem os relacionamentos diretos e indiretos desses atores (Halinen et al., 1999). Além disso, chama-se a atenção para o fato de que, ao invés do papel de mediador (Forsgren \& Olsson, 1992; Rezende \& Duarte, 2004), o poder, via fontes de poder, logra assumir o papel de moderador em mudanças pós-aquisição internacional, nos relacionamentos da adquirida com fornecedores e compradores. De alguma forma, isso representa novo entendimento acerca dessa variável, à medida que a nossa revisão de literatura internacional e nacional não identificou nenhum resultado correlato.

É também mister assinalar que o presente trabalho atende à sugestão de pesquisa de Öberg e Holstrom (2006, p. 1273). Especificamente, esses autores apontaram que o equilíbrio de poder e a dependência entre atores emergiram como resultados importantes da pesquisa empreendida. Porém, como os dados coletados e analisados não lhes permitiram estabelecer relações entre esses construtos, os autores suecos sugeriram que estudos futuros poderiam enveredar por esse caminho. Portanto, ao construir um modelo por meio do qual são derivadas cinco hipóteses que consideram as relações entre os construtos processos de aquisição internacional, fontes de poder e tipos de mudanças pós-aquisição, o nosso estudo apresenta um avanço em direção da realização de testes empíricos futuros.

A despeito de tais contribuições, algumas limitações deste trabalho podem eventualmente limitar o seu alcance ${ }^{(3)}$. A primeira delas diz respeito ao setor selecionado, alimentício, o que, por si só, impõe configurações particulares de relacionamentos e, principalmente, relações de poder entre compradores e fornecedores. Isso nos leva a indagar até que ponto os resultados aqui apresentados podem diferir em termos setoriais. Também nos leva a sugerir cautela para o teste do modelo desenvolvido neste trabalho, se contemplam os outros setores industriais. O segundo ponto se refere à utilização da literatura de canais de distribuição como aporte teórico à perspectiva de redes industriais para aprofundamento da variável poder. Apesar de a considerarmos como a literatura mais adequada para os fins desta pesquisa, conforme justificativa apresentada no decorrer do artigo, é imprescindível reconhecer a existência de outras literaturas sobre poder interorganizacional, notadamente a de cadeias globais de produção (Dicken, 1998; Gereffi \& Korzeniewicz, 1994) e a teoria crítica em negócios internacionais (Carr, 2006; Faria, 2007). Acreditamos que a utilização de uma dessas literaturas pode revelar relações entre os construtos processos de aquisição internacional, fontes de poder e tipos de mudanças pós-aquisição que o presente estudo, em função da nossa opção teórico-metodológica, não foi capaz de desvendar. Em especial para a teoria crítica, tal limitação reveste-se em oportunidade de pesquisa, à medida que, segundo Faria (2007, p. 35), essa abordagem "ainda não foi aplicada ao âmbito específico das redes”.

Artigo recebido em 28.08.2008. Aprovado em 31.07.2009.

\section{NOTAS}

\footnotetext{
${ }^{1}$ A coletânea de artigos, organizada pelo Prof. Hemais, C. (Ed.). (2004). O desafio dos mercados externos: teoria e prática na internacionalização da firma (Vol. 1). Rio de Janeiro: Editora Mauad e Hemais, C. (Ed.). (2005). O desafio dos mercados externos: teoria e prática na internacionalização da firma (Vol. 2). Rio de Janeiro: Editora Mauad, contém alguns trabalhos desenvolvidos no Brasil que utilizaram como arcabouço teórico a perspectiva de redes industriais no âmbito da internacionalização de empresas.
} 
${ }^{2} \mathrm{O}$ caso descrito e analisado neste artigo foi extraído de uma ampla pesquisa conduzida pelos autores do artigo, cujo objetivo foi o de analisar a influência de processos de aquisição internacional em redes. O estudo original contemplou quatro casos, envolvendo a realização de 37 entrevistas com representantes da adquirente, adquirida, fornecedores e compradores. Além disso, contou com amplo levantamento de dados secundários, a partir de diversas fontes de dados. Os autores agradecem à Fundação de Amparo à Pesquisa do Estado de Minas Gerais [FAPEMIG], que apoiou financeiramente o projeto original de pesquisa.

${ }^{3}$ Agradecemos ao parecerista anônimo por nos chamar atenção para esses dois pontos.

\section{REFERÊNCIAS BIBLIOGRÁFICAS}

Anderson, H., Havila, V., \& Salmi, A. (2001). Can you buy a business relationship? On the importance of customer and supplier relationships in acquisitions. Industrial Marketing Management, 30(7), 575-586.

Anderson, H., Holtström, J., \& Öberg, C. (2003, September). Are mergers or acquisitions expected to affect customer and supplier relationships? An analysis of decisions taken by a competitive authority. Proceedings of the Annual IMP Conference. Lugano, Switzerland, 19.

Anderson, J., Häkansson, H., \& Johanson, J. (1994). Dyadic business relationships within a business network context. Journal of Marketing, 58(4), 1-15.

Anderson, U., Forsgren, M., \& Holm, U. (2002). The strategic impact of external networks: subsidiary performance and competence development in the multinational corporation. Strategic Management Journal, 23(11), 979-996.

Araújo, L. (2003). Narratives, path dependence and case studies. Economia \& Gestão, 3(6), 11-22.

Barros, B. (2003). Fusões e aquisições: entendendo as razões do sucesso e do fracasso. São Paulo: Atlas.

Berthon, P., Pitt, L., Ewing, M., \& Bakkeland, G. (2003). Norms and power in marketing relationships: alternative theories and empirical evidence. Journal of Business Research, 56(9), 699-709.

Bocconcelli, R., Snehota, I., \& Tunisini, A. (2006). Network relationships and corporate acquisitions outcomes. The IMP Journal, 1(2), 1-55.

Brito, C. (1999). Issue-based nets: a methodological approach to the sampling issue in industrial networks research. Qualitative Market Research: An International Journal, 2(2), 92-102.

Brown, J., Lusch, R., \& Nicholson, C. (1995). Power and relationship commitment: their impact on marketing channel member performance. Journal of Retailing, 71, 363-392.

Cançado, V., \& Tanure, B. (2005). Fusões e aquisições: aprendendo com a experiência brasileira. $R A E, 45(2), 10-22$.

Carr, A. (2006). What it means to be "critical" in relation to international business: a case of the appropriate conceptual lens. Critical perspectives on international business, 2(2), p.79-90.

Child, J., Faulkner, D., \& Pitkethly, R. (2001). The management of international acquisitions. Oxford: University Press.

Cook, K. (1977). Exchange and power in networks of interorganizational relations. The Sociological Quarterly, 18(1), 62-82.

Datta, D. (1991). Organizational fit and acquisition performance: effects of post-acquisition integration. Strategic Management Journal, 12(4), 281-297. 
Dicken, P. (1998). Global shift: transforming the world economy. New York: The Guilford Press.

Duarte, R. (2001). Cross-border acquisitions and changes in domestic management practices - the case of Brazil. Unpublished Ph.D thesis, University of Cambridge, Cambridge, UK.

Duarte, R. (2003, setembro) The logic underlying post-acquisition change. Anais do Encontro Nacional da Associação Nacional de Pós-Graduação e Pesquisa em Administração, Atibaia, São Paulo, Brasil, 27.

Dubois, A., \& Gaade, L-E. (2002). Systematic combining: an abductive approach to case research. Journal of Business Research, 55(7), 553-560.

Easton, G., \& Lundgren, A. (1992). Changes in industrial networks as flow through nodes. In B. Axelsson \& G. Easton (Eds.), Industrial networks: a new view of reality (pp. 89-104). London: Routledge.

Eiriz, V., \& Wilson, D. (2006). Research in relationship marketing: antecedents, traditions and integration. European Journal of Marketing, 40(3/4), 275-291.

Eisenhardt, K. (1989). Building theories from case study research. Academy of Management Review, 14(4), 532-550.

El-Ansary, A., \& Stern, L. (1972). Power measurement in the distribution channel. Journal of Marketing Research, 9(1), 47-52.

Emerson, R. (1962). Power-dependence relations. American Sociological Review, 27(1), 31-41.

Faria, A. (2007). Uma proposta de framework em gerência estratégica de redes verticais. Revista de Administração Contemporânea, 11(1ª Edição Especial), 33-54.

Faria, A., \& Wensley, R. (2002). In search of 'interfirm management' in supply chains: recognizing contradictions of language and power by listening. Journal of Business Research, 55(7), 603-610.

Forsgren, M., \& Olsson, U. (1992). Power balancing in an international business network, In M. Forsgren \& J. Johanson (Eds.), Managing networks in international business (pp. 178-192). Philadelphia, Penn: Gordon and Breach, 1992.

Frazier, G. (1983). On the measurement of interfirm power in channels of distribution. Journal of Marketing Research, 20(2), 158-166.

Freitas, M., Rezende, S., \& Castro, J. (2008). Mudanças pós-aquisição internacional na rede de fornecedores da adquirida. Revista de Administração Contemporânea, 12(3), 811-834.

Gaski, J. (1984). The theory of power and conflict in channels of distribution. Journal of Marketing, 48(3), 9-29.

George, A., \& Bennett, G. (2005). Case studies and theory development in the social sciences. Cambridge: MIT Press.

Gereffi, G., \& Korzeniewicz, M. (1994). Commodity chains and global capitalism. Westport, CT: Praeger Publishers.

Golden, B. (1992). The past is the past - or is it? The use of retrospective accounts as indicators of past strategy. Academy of Management Journal, 35(4), 848-860.

Goldstone, J. (1997). Methodological issues in comparative macrosociology. Comparative Social Research, 16, 107-120. 
Graebner, M., \& Eisenhardt, K. (2004). The seller's side of the story: acquisitions as courtship and governance as syndicate in entrepreneurial firms. Administrative Science Quarterly, 49(3), 366-403.

Häkansson, H. (1982). International marketing and purchasing of industrial goods: an interaction approach. Hampshire: John Wiley \& Sons.

Häkansson, H., \& Ford, D. (2002). How should companies interact in business networks? Journal of Business Research, 55(2), 133-139.

Häkansson, H., \& Snehota, I. (1989). No business is an island: the network concept of business strategy. Scandinavian Journal of Management, 5(3), 187-200.

Häkansson, H., \& Snehota, I. (1995). Developing relationships in business networks - a literature review. London: Routledge.

Halinen, A., Salmi, A., \& Havila, V. (1999). From dyadic change to changing business networks: an analytical framework. Journal of Management Studies, 36(6), 779-794.

Halinen, A., \& Törnroos, J-A. (2005). Using case methods in the study of contemporary business networks. Journal of Business Research, 58, 1285-1297.

Haspeslagh, P., \& Jemison, D. (1991). Managing acquisitions: creating value through corporate renewal. New York: The Free Press.

Havila, V., \& Salmi, A. (2000). Spread of change in business networks: an empirical study of mergers and acquisitions in the graphic industry. Journal of Strategic Marketing, 8(2), 105-119.

Havila, V., \& Salmi. A. (2002). Network perspectives on international mergers and acquisitions: what more do we see? In V. Havila, M. Forsgren, \& H. Häkansson (Eds.), Critical perspectives on internationalization (pp. 457-472). Oxford: Pergamon.

Hertz, S. (1998). Domino effects in international networks. Journal of Business to Business Marketing, 5(3), 3-31.

Hilal, A., \& Hemais, C. (2001, setembro). Da escola de Uppsala à escola nórdica de negócios internacionais: uma revisão analítica. Anais do Encontro Nacional da Associação Nacional de Pós-Graduação e Pesquisa em Administração, Campinas, SP, Brasil, 25.

Hunt, S., \& Nevin, J. (1974). Power in a channel of distribution: sources and consequences. Journal of Marketing Research, 11(2), 186-193.

Jemison, D., \& Sitkin, S. (1986). Corporate acquisitions: a process perspective. Academy of Management Review, 11, 145-163.

Jick, T. (1979). Mixing qualitative and quantitative methods: triangulation in action. Administrative Science Quarterly, 24(4), 602-610.

Johnson, J., Sakano, T., Cote, J., \& Onzo, N. (1993). The exercise of interfirm power and its repercussions in U.S.-Japanese channel relationships. Journal of Marketing, 57(2), 1-10.

Kutschker, M. (1982). Power and dependence in industrial marketing. In H, Häkansson (Ed.), International marketing and purchasing of industrial goods (pp. 369-380). Hampshire: John Wiley \& Sons.

Lusch, R. (1976). Sources of power: their impact on intrachannel conflict. Journal of Marketing Research, 136(4), 382-390.

Miles, M., \& Huberman, A. (1994). Qualitative data analysis: an expanded sourcebook. London: Sage. 
Öberg, C., Henneberg, S., \& Mouzas, S. (2007). Changing network pictures: evidence from mergers and acquisitions. Industrial Marketing Management, 36(7), 926-940.

Öberg, C., \& Holström, J. (2006). Are mergers and acquisitions contagious? Conceptualising parallel M\&As among customers and suppliers. Journal of Business Research, 59(12), 1267-1275.

Poldony, J., \& Page, K. (1998). Network forms of organization. Annual Review of Sociology, 24, 57-76.

Provan, K., Beyer, J., \& Kruytbosch, C. (1980). Environmental linkages and power in resourcedependence relations between organizations. Administrative Science Quarterly, 25(2), 200-225.

Ragin, C. (1987). The comparative method: moving beyond qualitative and quantitative strategies. Berkely: University of California Press.

Rezende, S., \& Duarte, R. (2004). Post-acquisition changes beyond the dyad: power at the net level in cross-border acquisitions. Brazilian Administration Review, 1(1), 67-80. Recuperado em 19 abril, 2007, de http://www.anpad.org.br/periodicos/arq_pdf/a_619.pdf

Ritter, T., \& Ford, D. (2004). Interactions between suppliers and customers in business markets. In H. Häkansson, D. Harrison, \& A. Waluszewski (Eds.), Rethinking marketing: developing a new understanding of markets (pp. 99-116). London: Wiley.

Shrivastava, P. (1986). Post-merger integration. The Journal of Business Strategy, 7(1), 65-76.

United Nations Conference on Trade and Development. (2000). World investment report 2000. New York: United Nations.

United Nations Conference on Trade and Development. (2006). World investment report 2006. New York: United Nations.

Wilkinson, I. (1979). Power and satisfaction in channels of distribution. Journal of Retailing, 55(2), 79-94.

Wilkinson, I., \& Kipnis, D. (1978). Interfirm use of power. Journal of Applied Psychology, 63(3), 315-320.

Wilkinson, I., \& Young, L. (2002). On cooperating firms, relations and networks. Journal of Business Research, 55(2), 123-132. 